\title{
Methods of Blood Pressure Assessment Used in Milestone Hypertension Trials
}

\author{
Yi Chen Lei Lei Ji-Guang Wang \\ Centre for Epidemiological Studies and Clinical Trials, Shanghai Key Laboratory of \\ Hypertension, The Shanghai Institute of Hypertension, Department of Hypertension, \\ Ruijin Hospital, Shanghai Jiaotong University School of Medicine, Shanghai, China
}

\section{Keywords}

Blood pressure $\cdot$ Assessment $\cdot$ Methods $\cdot$ Clinical trials $\cdot$ Hypertension

\begin{abstract}
In the present review, we summarized the blood pressure (BP) measurement protocols of contemporary outcome trials in hypertension. In all these trials, clinic BP was used for the diagnosis and therapeutic monitoring of hypertension. In most trials, BP was measured in the sitting position with mercury sphygmomanometers or automated electronic BP monitors by trained observers. BP readings were taken on each occasion at least twice with a 30-to-60-s interval after 5 min of rest. Details regarding the arm side, cuff size, and the timing of BP measurement were infrequently reported. If clinic BP continues being used in future hypertension trials, the measurement should strictly follow current guidelines. The observers must be trained and experienced, and the device should be validated by automated electronic BP monitors. On each occasion, BP readings should be taken 2-3 times. The time interval between successive measurements has to be 30-60 s, and the resting period before the measurement should be at least $5 \mathrm{~min}$ in the supine or seated position and 1-3 min standing. BP should usually be measured in the seated position. The higher arm side and an appropriate size cuff should be chosen and noted. BP should be measured at defined trough hours. Automated office BP measurement has recently been used and seems to have less white-coat effect. The out-of-office BP measurement, either ambulatory or home BP monitoring, was only used in a subset of study participants of few hypertension trials. Future trials should consider these novel office or out-of-office BP measurements in guiding the therapy and preventing cardiovascular events.




\section{Introduction}

Accurate blood pressure (BP) measurement is critical for the clinical management of hypertension and for clinical trial research in hypertension as well. The methodology of BP measurement therefore has to be carefully chosen to assure the accuracy of BP measurement in a hypertension trial. Indeed, small discrepancies in BP measuring protocols may have substantial impact on the recorded BP levels and subsequent therapeutic decisions during a trial, and sometimes on the results of the whole trial.

In principle, the methods of BP measurement used in a hypertension trial should stringently follow most recent guideline recommendations [1-3]. If the results of such a trial would be clinically relevant for clinical practice and used for guideline recommendations, the corresponding methods of BP measurement may also be used to formulate recommendations on BP measurement in clinical practice.

Over the years, dozens of clinical trials in hypertension had been conducted with various $\mathrm{BP}$ measuring techniques and protocols. Because the technology and knowledge for BP measurement have been advancing rapidly, the BP measuring techniques and protocols changed from the early to the most recent trials in hypertension. In this review article, we will summarize the BP measurement protocols used in the milestone hypertension trials [4-60] and explore the clinical relevance and implications for the management of hypertension.

\section{Methodological Issues of BP Assessment in Milestone Hypertension Trials}

A literature search limited to outcome clinical trials published in English between January 1, 1990, and April 1, 2017, was performed using PubMed with the keywords "hypertension" or "blood pressure," "randomized controlled trial", and "cardiovascular event." Additional relevant trials were included from the references of the identified studies. Selected studies were randomized controlled outcome trials with a blinded or open design. We excluded studies of a surrogate outcome measure or in patients with congestive heart failure, end-stage renal disease on dialysis, or acute stroke ( $<30$ days after onset). Relevant information was also obtained from prior publications related to the trial design of the individual studies.

We selected 36 milestone hypertension trials that formed the basis for the past and current hypertension management guidelines. Although ambulatory BP monitoring was performed in a subset of randomized patients in some of these trials, such as the Hypertension Optimal Treatment (HOT) [16], Systolic Blood Pressure Reduction Trial (SPRINT) [58], and Valsartan Antihypertensive Long-term Use Evaluation (VALUE) trials [38], clinic or office BP measurement was used in all these milestone hypertension trials. We evaluated 9 different aspects of BP measurement (Table 1) in terms of the accordance with recent BP measurement guidelines [1-3].

\section{Observers}

Physicians measured BP in most of the earlier trials [6-8]. However, non-physician health professionals, such as nurses, were increasingly involved in many of the recent trials [22, 29-32]. In addition to the increased use of automated BP monitors in clinical practice and research, several other reasons drove this shift. Although physicians are usually adequately trained to measure BP, they do not often measure BP in complete compliance with the standards of BP measurement guidelines [61]. When an auscultatory device (mercury, aneroid, or hybrid) is used, they often have reading bias, in other words, digit preference and commonly round $B P$ readings to 0 or 5 . In addition, the white-coat effect may also dilute the validity and usefulness of BP measured by physicians. Therefore, some experts recommended that physi- 
Pulse

Chen et al.: Methods of Blood Pressure Assessment Used in Milestone Hypertension

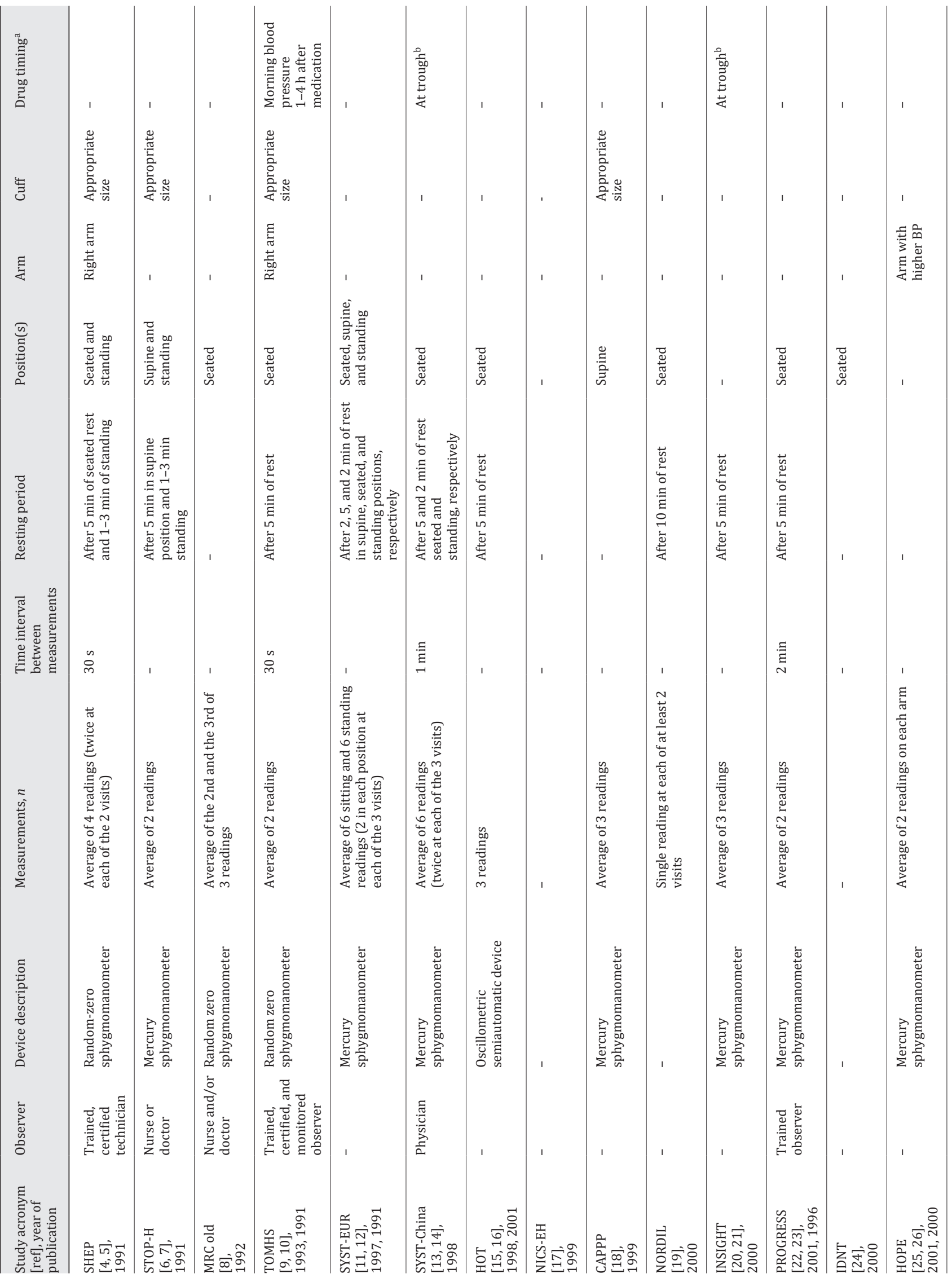


Pulse

Chen et al.: Methods of Blood Pressure Assessment Used in Milestone Hypertension Trials

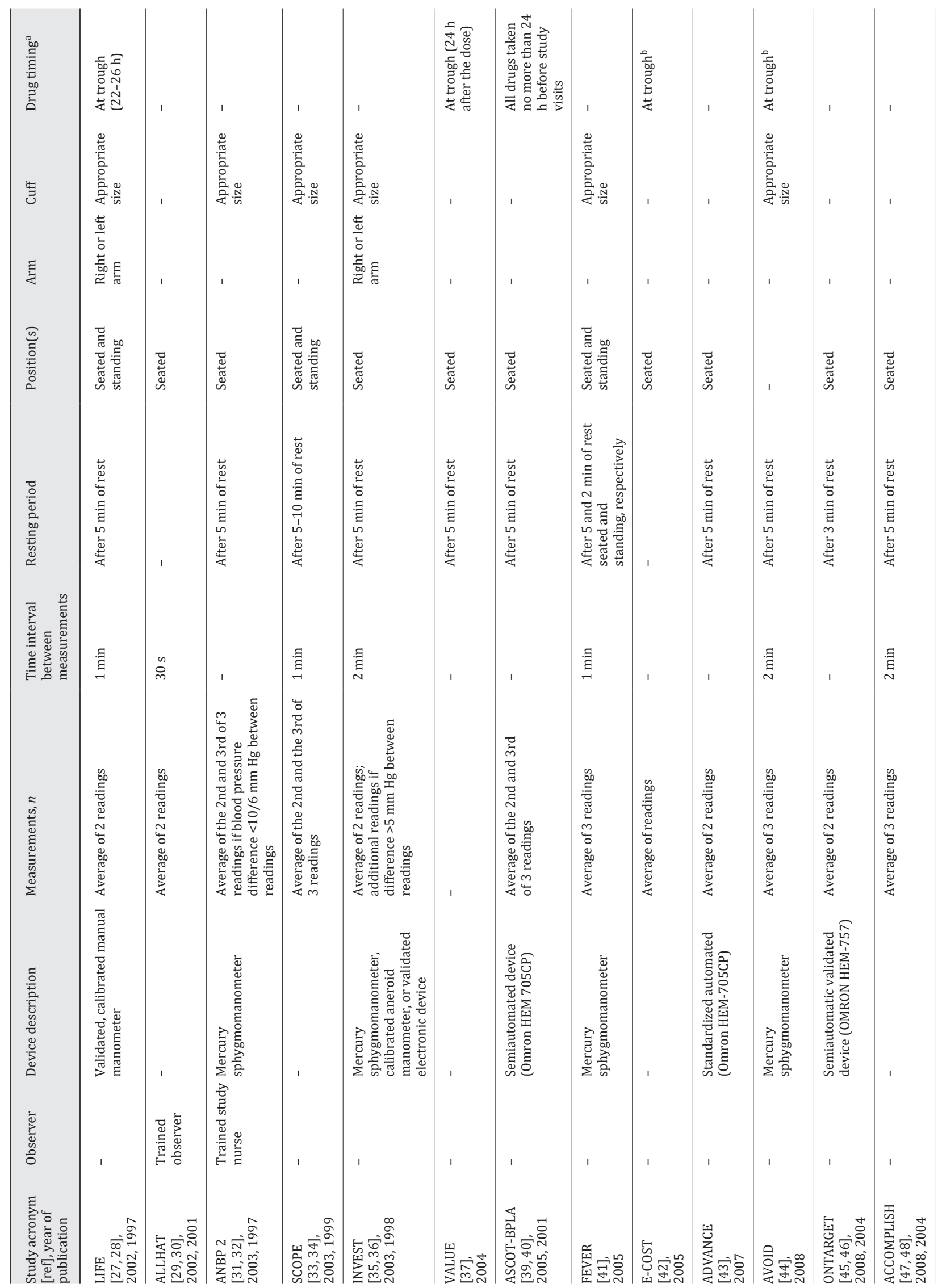




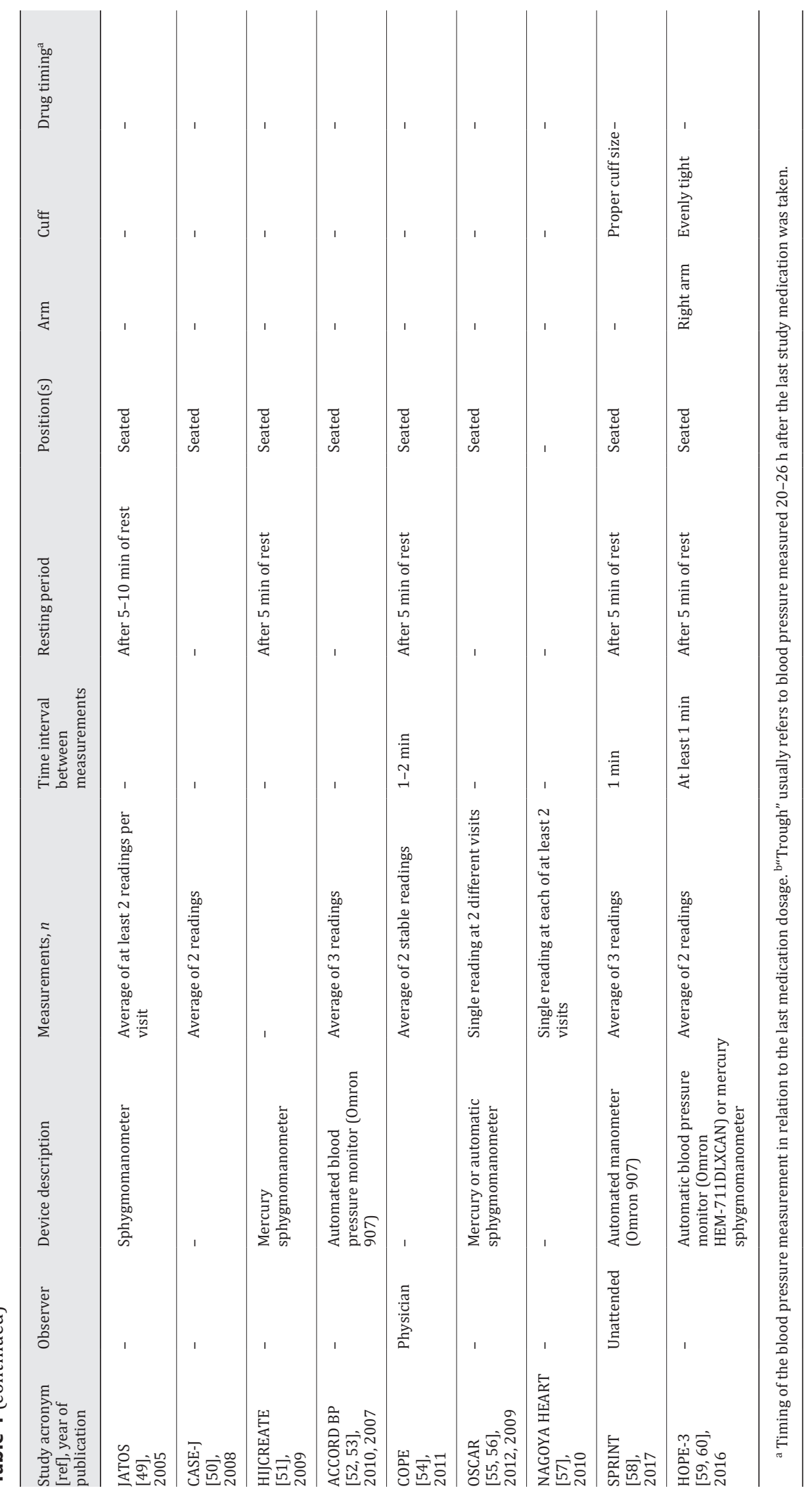


cians should not measure BP themselves but should rely on BPs measured by trained observers or using validated automated devices to improve the quality of care of hypertensive patients in general and the accuracy of BP assessment in clinical research in particular [61].

However, people believe that even though BP is measured by nurses, other "trained observers," or automated devices, the white-coat effect is still possible in clinic BP measurement. Many patients still become anxious in the clinical setting even in the absence of physicians. The presence of a nurse or other trained observers may lead to conversation and therefore increase BP. That is the rationale for establishing unattended BP measurement facilities. Such an unattended BP measurement was used in the recent Systolic Pressure Reduction Intervention Trial (SPRINT) [58]. In SPRINT, clinic BP was measured automatically 3 times with a validated oscillometric device with the patient being quiet and isolated in a room [62]. This methodology has been labelled as automated office BP measurement (AOBP). This so-called AOBP used in the SPRINT trial had 2 key elements. First, everybody except the patient him/herself was out of the room during measurements and the resting period prior to measurements. Second, the BP measurement device (Omron 907, Kyoto, Japan) was preset to wait for 5 min before measurements were started. BP was measured 3 times at a 1-min interval.

This unattended BP measurement is considered superior to conventional office BP measurement because it reduces the white-coat effect and shows a better correlation with ambulatory BP and target organ damage than conventional office BP [63, 64]. This approach to measuring BP is, in some researchers' opinion, probably better than conventional office BP measurement methods. However, systolic BP, assessed by unattended measurements, is lower than measurements in the presence of a physician or nurse [65, 66]. According to some researchers, the blood-pressure levels attained in the SPRINT intensive treatment group (systolic BP $<120 \mathrm{~mm} \mathrm{Hg}$ ) might correspond to a conventional office systolic BP $<136 \mathrm{~mm} \mathrm{Hg}$, which is more or less the same as the currently recommended therapeutic target of adequate BP control (systolic BP $<140 \mathrm{~mm} \mathrm{Hg}$ ) [65].

The 2005 recommendations on BP measurement do not mandate who should measure $\mathrm{BP}$ but do require that the observer be properly trained $[1,2]$. AOBP was recommended in the 2013 European Society of Hypertension guidelines for the management of hypertension as a superior method to improve reproducibility and to make office BP values closer to daytime ambulatory and home BP [67].

\section{Devices}

Before electronic BP monitors became readily available in clinical practice a few decades ago, mercury sphygmomanometers were the major instrument for BP measurement in earlier clinical trials, including the Hawksley random-zero sphygmomanometer [4, 8]. However, even in the era of electronic BP measuring devices, both aneroid and mercury sphygmomanometers had been used in parallel with automated and semiautomated electronic devices in the International Verapamil SR-Trandolapril Study (INVEST) [35, 36]. In fact, this multipledevice approach was also seen in several other multicenter clinical trials, such as the recent Heart Outcomes Prevention Evaluation-3 (HOPE-3) trial $[59,60]$, and even in the singlecenter Olmesartan and Calcium Antagonists Randomized (OSCAR) trial [55, 56].

The standard sphygmomanometer has been the mainstay of clinic BP measurement since $\mathrm{BP}$ could be measured noninvasively. This technique usually requires a mercury manometer. It has been removed from clinical practice in several countries and will eventually be eliminated from BP measurement in all countries not before long because of serious environmental concerns about mercury pollution. In addition, manual auscultatory BP measurement is prone to observers' error or bias. For these reasons, manual BP measurement is gradually being supplanted by automated techniques. 
Currently, the most widely used mercury-free devices are automated oscillometric BP monitors [68]. Some professional oscillometric devices allow consecutive repeated automated measuring and averaging and simultaneous two-arm measurements, with some optional functions, such as associated auscultatory BP measurement mode, detection of irregular heart beat or specifically atrial fibrillation, automated memory, and computer link or blue-tooth transfer of readings. The use of oscillometric devices for office BP measurement is still debatable in the presence of atrial fibrillation. However, the results of recent studies suggested that in atrial fibrillation, oscillometric BP monitors had similar accuracy in both systolic and diastolic BP measurements as the repeated auscultatory method [69].

Whatever devices are used, they should be regularly calibrated. When automated BP monitors are used, they should be validated. In the latter case, mercury column-based sphygmomanometers, although being phasing out in office BP measurement, are still critical for evaluating the accuracy of algorithm-based electronic devices [1].

\section{Body Position and Resting Period}

Most studies reported seated BP levels, and the resting time before the initial measurement varied from 3 to $10 \mathrm{~min}$, with the most frequent resting period being $5 \mathrm{~min}$. In several early studies (before 2000), BP was measured in the supine position [18] or in both the supine and standing positions [7], usually after $5 \mathrm{~min}$ rest in the supine position. In some other studies, $\mathrm{BP}$ was measured in both the seated and standing positions [4, 27, 33, 41]. In the standing position, BP was usually measured after 1-3 min.

\section{Number of BP Readings and Time Interval}

In most trials, multiple (2-6) BP readings were obtained. However, the ultimately recorded value varied from the lowest of a number of readings to an average of 2 or 3 readings or the last 2 of 3 readings. The time interval between consecutive readings ranged from 30 to 120 s (Table 1 ).

\section{Arm Side and Cuff Size}

$\mathrm{BP}$ was measured on the upper arm in almost all trials, although this was rarely acknowledged explicitly. The arm side for BP measurement was also infrequently noted. However, most commonly it was the right arm or the arm with the higher BP value. The actual protocol used to determine the correct cuff size was rarely stated. However, an "appropriate size" was frequently delineated. Other aspects, such as whether the brachial artery was positioned at the "heart level" as per guideline, could not be assessed in most trials.

\section{Timing of BP Measurement}

"Trough" BP levels were most commonly obtained although indicated in only a minority of trials, and the trough time is usually at 20-26 h after the last antihypertensive medication dosage.

The BP measurement guidelines do not mandate timing of BP measurement. However, for the purpose of comparability between trial groups and over time, BP should be measured at "trough" effect hours in all comparison studies. This is indeed mandatory for the approval of any medication by the US Food and Drug Administration [70]. For a claimed once-daily medication, the trough efficacy of BP lowering must be at least $50 \%$ of the peak effect [70]. However, the timing in relation to the last medication dosage is rarely discussed in the guidelines [1-3].

\section{Summary of Recommendations for Optimal BP Measurement}

There is no specific guideline for BP measurement in hypertension trials. In general, BP measurement should strictly follow the current recommendations or guidelines $[1,2]$. 
Chen et al.: Methods of Blood Pressure Assessment Used in Milestone Hypertension Trials

Taking into account accuracy as well as practicability, the best scenario for the 9 aspects of BP measurements in hypertension trials would be as follows: (1) the observers are trained and experienced; (2) the device should be automated electronic BP monitor and should have been previously validated and regularly calibrated; (3) on each occasion, BP should be measured 2-3 times, and an average of 2 or 3 readings should be taken; (4) the time interval between successive measurements has to be 30-60 s; (5) the resting period before measurement has to be at least $5 \mathrm{~min}$ in the supine or seated position and awake, and 1-3 min standing; (6) BP should usually be measured in the seated position, and under some circumstances in the supine or standing position; (7) the higher arm side should be chosen and noted; (8) an appropriate size cuff should be chosen, and the size of the cuff should be noted; and (10) BP should be measured at trough hours, which should be defined, and the exact time of BP measurement should be noted.

In all hypertension trials, these aspects have to be defined a priori in the protocol and recorded in the case report forms. The application can be monitored during the execution of the trial.

\section{Clinical Implications}

Office BP measurement has been used for the diagnosis and therapeutic monitoring of hypertension for more than a century. Office BP still has a role in the screening, diagnosis, and follow-up of hypertension, despite its apparent drawback of overdiagnosis and underdiagnosis of hypertension because of the white-coat and masked hypertension, respectively [71].

AOBP seems to be a superior office BP measurement method. However, it should be recognized that although the $\mathrm{BP}$ values of $\mathrm{AOBP}$ may be more strongly associated with hypertension-related target organ damage, there is no evidence to date that treatment decisions based on AOBP yield better cardiovascular outcomes than the conventional office BP measurement [72]. More research, especially outcome trial research, is needed before a universal recommendation can be made on the use of AOBP in clinical practice. A lower cutoff value of 135/85 mm Hg has been proposed when AOBP is used for the diagnosis of hypertension, as compared with the conventional office BP measurement of 140/90 $\mathrm{mm} \mathrm{Hg}$ $[72,73]$ The results of a recent study in 3,627 participants also suggested that $135 / 85 \mathrm{~mm}$ $\mathrm{Hg}$ may be an appropriate threshold for the diagnosis of hypertension in older subjects using AOBP [74].

As compared with any office BP measurement, out-of-office BP measurement, such as ambulatory and home BP monitoring, has apparent advantages. It is devoid of the whitecoat effect, and by comparing with office BP, it may identify white-coat hypertension. It may help in the diagnosis of masked hypertension, including nocturnal hypertension [75]. It may also improve cardiovascular prediction by measuring nocturnal dipping, morning $\mathrm{BP}$ surge, and reading-to-reading BP variability [76]. Nonetheless, the superiority of ambulatory and home BP monitoring over office BP in guiding antihypertensive therapy, in terms of cardiovascular disease prevention, has not yet been fully proven by randomized controlled trials [77], needless to say that its availability in both high- and low-income settings is still limited.

Future randomized clinical trials should consider the use of these novel office or out-ofoffice BP measurements in the guidance of antihypertensive therapy and prevention of cardiovascular events. 
Chen et al.: Methods of Blood Pressure Assessment Used in Milestone Hypertension Trials

\section{Disclosure Statement}

Dr. Wang reports having received grants from the National Natural Science Foundation of China (81270373, 81470533, and 91639203), the Ministry of Science and Technology (2015AA020105-06 and 2016YFC1300100), and the Shanghai Commission of Science and Technology (15XD1503200), and lecture and consulting fees from Astra-Zeneca, Bayer, Daiichi-Sankyo, MSD, Omron, Pfizer, Sanofi, Servier, and Takeda. The other authors declare that they have no conflicts of interest.

\section{References}

1 Pickering TG, Hall JE, Appel LJ, Falkner BE, Graves J,Hill MN, et al: Recommendations for blood pressure measurement in humans and experimental animals: part 1:blood pressure measurement in humans: a statement for professionals from the Subcommittee of Professional and Public Education of the American Heart Association Council on High Blood Pressure Research. Circulation 2005;111:697-716.

2 O’Brien E, Asmar R, Beilin L, Imai Y, Mancia G, Mengden T, et al: Practice guidelines of the European Society of Hypertension for clinic, ambulatory and self blood pressure measurement. J Hypertens 2005;23:697-701.

3 O’Brien E, Asmar R, Beilin L, Imai Y, Mallion JM, Mancia G, et al: European Society of Hypertension recommendations for conventional, ambulatory and home blood pressure measurement. J Hypetens 2003;21:821-848.

4 The Systolic Hypertension in the Elderly Program (SHEP) Cooperative Research Group: Prevention of stroke by antihypertensive drug treatment in older persons with isolated systolic hypertension. Final results of the SHEP. JAMA 1991;265:3255-3264.

5 Labarthe DR, Blaufox MD, Smith WM, Lacy CR, Schnaper H, LaBaw F, et al: Systolic Hypertension in the Elderly Program (SHEP). Part 5: Baseline blood pressure and pulse rate measurements. Hypertension 1991;17(suppl 3):II62- II76.

6 Dahlof B, Lindholm LH, Hansson L, Schersten B, Ekbom T, Wester PO: Morbidity and mortality in the Swedish Trial in Old Patients with Hypertension (STOP-Hypertension). Lancet 1991;338:1281-1285.

7 Dahlöf B, Hansson L, Lindholm L, Råstam L, Scherstén B, Wester PO: STOP-Hypertension: Swedish trial in old patients with hypertension. J Hypertens 1986;4:511-513.

8 MRC Working Party: Medical Research Council trial of treatment of hypertension in older adults: principal results. BMJ 1992;304:405-412.

9 Neaton JD, Grimm RH Jr, Prineas RJ, Stamler J, Grandits GA, Elmer PJ, et al: Treatment of Mild Hypertension Study. Final results. JAMA 1993;270:713-724.

10 Treatment of Mild Hypertension Research Group: A randomized, placebo-controlled trial of a nutritionalhygienic regimen along with various drug monotherapies. Arch Intern Med 1991;151:1413-1423.

11 Staessen JA, Fagard R, Thijs L, Celis H, Arabidze GG, Birkenhäger WH, et al: The Systolic Hypertension in Europe (SYST-EUR) Trial Investigators. Randomised double-blind comparison of placebo and active treatment for older patients with isolated systolic hypertension. Lancet 1997;350:757-764.

12 Amery A, Birkenhäger W, Bulpitt CJ, Clément D, De Leeuw P, Dollery CT, et al: SYST-EUR: a multicentre trial on the treatment of isolated systolic hypertension in the elderly: objectives, protocol, and organization. Aging Clin Exp Res 1991;3:287-302.

13 Liu L, Wang JG, Gong L, Liu G, Staessen JA, Systolic Hypertension in China (SYST-China) Collaborative Group. Comparison of active treatment and placebo in older Chinese patients with isolated systolic hypertension. J Hypertens 1998;16:1823-1829.

14 Wang JG, Liu G, Wang X, Zhang S, Sun M, Pan X, et al: Long-term blood pressure control in older Chinese patients with isolated systolic hypertension: a progress report on the SYST-China trial. J Hum Hypertens 1996; 10:735-742.

15 Hansson L, Zanchetti A, Carruthers SG, Dahlof B, Elmfeldt D, Julius S, et al: Effects of intensive blood-pressure lowering and low-dose aspirin in patients with hypertension: principal results of the Hypertension Optimal Treatment (HOT) randomised trial. HOT Study Group. Lancet 1998;351:1755-1762.

16 Mancia G, Omboni S, Parati G, Clement DL, Haley WE, Rahman SN, et al: Twenty-four hour ambulatory blood pressure in the Hypertension Optimal Treatment (HOT) study. J Hypertens 2001;19:1755-1763.

17 National Intervention Cooperative Study in Elderly Hypertensives Study Group: Randomized double-blind comparison of a calcium antagonist and a diuretic in elderly hypertensives. Hypertension 1999;34:11291133.

18 Hansson L, Lindholm LH, Niskanen L, Lanke J, Hedner T, Niklason A, et al: Effect of angiotensin converting enzyme inhibition compared with conventional therapy on cardiovascular morbidity and mortality in hypertension: the Captopril Prevention Project (CAPPP) randomised trial. Lancet 1999;353:611-616.

19 Hansson L, Hedner T, Lund-Johansen P, Kjeldsen SE, Lindholm LH, Syvertsen JO, et al: Randomised trial of effects of calcium antagonists compared with diuretics and beta-blockers on cardiovascular morbidity and mortality in hypertension: the Nordic Diltiazem (NORDIL) study. Lancet 2000;356:359-365. 
20 Brown MJ, Palmer CR, Castaigne A, de Leeuw PW, Mancia G, Rosenthal T, et al: Morbidity and mortality in patients randomised to double-blind treatment with a long-acting calcium-channel blocker or diuretic in the International Nifedipine GITS study: Intervention as a Goal in Hypertension Treatment (INSIGHT). Lancet 2000;356:366-372.

21 Mancia G, Omboni S, Parati G: Investigators of the INSIGHT ABPM substudy. Twenty-four hour ambulatory blood pressure in the International Nifedipine GITS Study Intervention as a Goal in Hypertension Treatment (INSIGHT). J Hypertens 2002;20:545-553.

22 PROGRESS Collaborative Group: Randomised trial of a perindopril-based blood-pressure-lowering regimen among 6,105 individuals with previous stroke or transient ischaemic attack. Lancet 2001;358:1033-1041.

23 PROGRESS Management Committee: Blood pressure lowering for the secondary prevention of stroke: rationale and design for Progress. J Hypertens 1996;14(suppl 2):S41-S45; discussion S45-S46.

24 Rodby RA, Rohde RD, Clarke WR, Hunsicker LG, Anzalone DA, Atkins RC, et al: The Irbesartan type II Diabetic Nephropathy Trial: study design and baseline patient characteristics. For the Collaborative Study Group. Nephrol Dial Transplant 2000;15:487-497.

25 Svensson P, de Faire U, Sleight P, Yusuf S, Ostergren J: Comparative effects of ramipril on ambulatory and office blood pressures: a HOPE substudy. Hypertension 2001;38:e28-e32

26 Yusuf S, Sleight P, Pogue J, Bosch J, Davies R, Dagenais G: Effects of an angiotensin-converting-enzyme inhibitor, ramipril, on cardiovascular events in high-risk patients. N Engl J Med 2000;342:145-153.

27 Dahlof B, Devereux RB, Kjeldsen SE, Julius S, Beevers G, de Faire U, et al: Cardiovascular morbidity and mortality in the Losartan Intervention For Endpoint reduction in hypertension study (LIFE): a randomized trial against atenolol. Lancet 2002;359:995-1003.

28 Dahlöf B, Devereux RB, de Faire U, Fyhrquist F, Hedner T, Ibsen H, et al: The Losartan Intervention For Endpoint reduction (LIFE) in Hypertension Study: rationale, design, and methods. Am J Hypertens 1997;10: 705-713.

29 The ALLHAT Officers and Coordinators for the ALLHAT Collaborative Research Group: Major outcomes in high-risk hypertensive patients randomized to angiotensin-converting enzyme inhibitor or calcium channel blocker vs diuretic: the Antihypertensive and Lipid-Lowering Treatment to Prevent Heart Attack Trial (ALLHAT). JAMA 2002;288:2981-2997.

30 Grimm RH Jr, Margolis KL, Papademetriou V, Cushman WC, Ford CE, Bettencourt J, et al: Baseline characteristics of participants in the Antihypertensive and Lipid Lowering Treatment to Prevent Heart Attack Trial (ALLHAT). Hypertension 2001;37:19-27.

31 Wing LM, Reid CM, Ryan P, Beilin LJ, Brown MA, Jennings GL, et al: A comparison of outcomes with angiotensinconverting enzyme inhibitors and diuretics for hypertension in the elderly. N Engl J Med 2003;348:583-592.

32 Australian comparative outcome trial of angiotensin-converting enzyme inhibitor and diuretic based treatment of hypertension in the elderly (ANBP2): objective and protocol. Clin Exp Pharmacol Physiol 1997; 24:188-192.

33 Lithell H, Hansson L, Skoog I, Elmfeldt D, Hofman A, Olofsson B, et al: The Study on Cognition and Prognosis in the Elderly (SCOPE): principal results of a randomized double-blind intervention trial. J Hypertens 2003;21: 875-886.

34 Hansson L, Lithell H, Skoog I, Baro F, Banki CM, Breteler M, et al: Study on cognition and prognosis in the elderly (SCOPE). Blood Press 1999;8:177-183

35 Pepine CJ, Handberg EM, Cooper-DeHoff RM, Marks RG,Kowey P, Messerli FH, et al: Acalcium antagonist versus a non-calcium antagonist hypertension treatment strategy for patients with coronary artery disease. The International Verapamil-Trandolapril Study (INVEST): a randomized controlled trial. JAMA 2003;290: 2805-2816.

36 Pepine CJ, Handberg-Thurmond E, Marks RG, Conlon M, Cooper-DeHoff R, Volkers P, et al: Rationale and design of the International Verapamil SR/Trandolapril Study (INVEST): an Internet-based randomized trial in coronary artery disease patients with hypertension. J Am Coll Cardiol 1998;32:1228-1237.

37 Julius S, Kjeldsen SE, Weber M, Brunner HR, Ekman S, Hansson L, et al: Outcomes in hypertensive patients at high cardiovascular risk treated with regimens based on valsartan or amlodipine: the VALUE randomised trial. Lancet 2004;363:2022-2031.

38 Pedersen OL, Mancia G, Pickering T, Høegholm A, Julius S, Kjeldsen SE, et al: Ambulatory blood pressure monitoring after 1 year on valsartan or amlodipine-based treatment: a VALUE substudy. J Hypertens 2007;25: 707-712.

39 Dahlof B, Sever PS, Poulter NR, Wedel H, Beevers DG, Caulfield M, et al: Prevention of cardiovascular events with an antihypertensive regimen of amlodipine adding perindopril as required versus atenolol adding bendroflumethiazide as required, in the Anglo-Scandinavian Cardiac Outcomes Trial-Blood Pressure Lowering Arm (ASCOT-BPLA): a multicenter randomized controlled trial. Lancet 2005;366:895-906.

40 Sever PS, Dahlöf B, Poulter NR, Wedel H, Beevers G, Caulfield M, et al: Rationale, design, methods and baseline demography of participants of the Anglo-Scandinavian Cardiac Outcomes Trial. J Hypertens 2001;19:11391147.

41 Liu L, Zhang Y, Liu G, Li W, Zhang X, Zanchetti A: The Felodipine Event Reduction (FEVER) Study: a randomized long-term placebo controlled trial in Chinese hypertensive patients. J Hypertens 2005;23:2157-2172.

42 Suzuki H, Kanno Y: Effects of candesartan on cardiovascular outcomes in Japanese hypertensive patients. Hypertens Res 2005;28:307-314. 
43 Advance Collaborative Group: Effects of a fixed combination of perindopril and indapamide on macrovascular and microvascular outcomes in patients with type 2 diabetes mellitus (the ADVANCE trial): a randomised controlled trial. Lancet 2007;370:829-840.

44 Parving HH, Persson F, Lewis JB, Lewis EJ, Hollenberg NK; AVOID Study Investigators. Aliskiren combined with losartan in type 2 diabetes and nephropathy. N Engl J Med 2008;358:2433-2446.

45 Ontarget Investigators: Telmisartan, ramipril, or both in patients at high risk for vascular events. N Engl J Med 2008;358:1547-1559

46 Teo K, Yusuf S, Sleight P, Anderson C, Mookadam F, Ramos B,et al: Rationale, design, and baseline characteristics of 2 large, simple, randomized trials evaluating telmisartan, ramipril, and their combination in high-risk patients: the Ongoing Telmisartan Alone and in Combination with Ramipril Global Endpoint Trial/Telmisartan Randomized Assessment Study in ACE Intolerant Subjects with Cardiovascular Disease (ONTARGET/ TRANSCEND) trials. Am Heart J 2004;148:52-61.

47 Jamerson K, Weber MA, Bakris GL, Dahlof B, Pitt B, Shi V, et al: Benazepril plus amlodipine or hydrochlorothiazide for hypertension in high-risk patients. N Engl J Med 2008;359:2417-2428.

48 Jamerson KA, Bakris GL, Wun CC, Dahlöf B, Lefkowitz M, Manfreda S, et al: Rationale and design of the Avoiding Cardiovascular events through COMbination therapy in Patients LIving with Systolic Hypertension (ACCOMPLISH) trial: the first randomized controlled trial to compare the clinical outcome effects of first-line combination therapies in hypertension. Am J Hypertens 2004;17:793-801.

49 JATOS Study Group: The Japanese Trial to Assess Optimal Systolic Blood Pressure in Elderly Hypertensive patients (JATOS): protocol, patient characteristics, and blood pressure during the first 12 months. Hypertens Res 2005;28:513-520.

50 Ogihara T, Nakao K, Fukui T, Fukiyama K, Ueshima K, Oba K, et al: Effects of candesartan compared with amlodipine in hypertensive patients with high cardiovascular risks: Candesartan Antihypertensive Survival Evaluation in Japan Trial. Hypertension 2008;51:393-398.

51 Kasanuki H, Hagiwara N, Hosoda S, Sumiyoshi T, Honda T, Haze K, et al: Angiotensin II receptor blocker-based vs. non-angiotensin II receptor blocker based therapy in patients with angiographically documented coronary artery disease and hypertension: the Heart Institute of Japan Candesartan Randomized Trial for Evaluation in Coronary Artery Disease (HIJCREATE). Eur Heart J 2009;30:1203-1212.

52 The ACCORD Study Group: Effects of intensive blood-pressure control in type 2 diabetes mellitus. N Engl J Med 2010;362:1575-1585.

53 Cushman WC, Grimm RH Jr, Cutler JA, Evans GW, Capes S, Corson MA, et al: Rationale and design for the blood pressure intervention of the Action to Control Cardiovascular Risk in Diabetes (ACCORD) trial. Am J Cardiol 2007; 99 (suppl):44i-55i.

54 Matsuzaki M, Ogihara T, Umemoto S, Rakugi H, Matsuoka H, Shimada K, et al: Prevention of cardiovascular events with calcium channel blocker-based combination therapies in patients with hypertension: a randomized controlled trial. J Hypertens 2011;29:1649-1659.

55 Ogawa H, Kim-Mitsuyama S, Matsui K, Jinnouchi T, Jinnouchi H, Arakawa K: Angiotensin II receptor blockerbased therapy in Japanese elderly, high-risk, hypertensive patients. Am J Med 2012;125:981-990.

56 Ogawa H, Kim-Mitsuyama S, Jinnouchi T, Matsui K, Arakawa K. Rationale, design and patient baseline characteristics of OlmeSartan and Calcium Antagonists Randomized (OSCAR) study: a study comparing the incidence of cardiovascular events between high-dose angiotensin II receptor blocker (ARB) monotherapy and combination therapy of ARB with calcium channel blocker in Japanese elderly high-risk hypertensive patients. Hypertens Res 2009;32:575-580.

57 Matsushita K, Muramatsu T, Kondo T, Maeda K, Shintani S, Murohara T; NAGOYA HEART Study Group: Rationale and design of the NAGOYA HEART Study: comparison between valsartan and amlodipine regarding morbidity and mortality in patients with hypertension and glucose intolerance. J Cardiol 2010;56:111-117.

58 Drawz PE, Pajewski NM, Bates JT, Bello NA, Cushman WC, Dwyer JP, et al: Effect of intensive versus standard clinic-based hypertension management on ambulatory blood pressure: results from the SPRINT (Systolic Blood Pressure Intervention Trial) ambulatory blood pressure study. Hypertension 2017;69:42-50.

59 Lonn E, Bosch J, Pogue J, Avezum A, Chazova I, Dans A, et al: Novel approaches in primary cardiovascular disease prevention: the HOPE-3 trial rationale, design, and participants' baseline characteristics. Can J Cardiol 2016;32:311-318.

60 Lonn EM, Bosch J, López-Jaramillo P, Zhu J, Liu L, Pais P, et al: Blood-pressure lowering in intermediate-risk persons without cardiovascular disease. N Engl J Med 2016;374:2009-2020.

61 Graves JW, Sheps SG: Does evidence-based medicine suggest that physicians should not be measuring blood pressure in the hypertensive patient? Am J Hypertens 2004;17:354-360.

62 Kjeldsen SE, Lund-Johansen P, Nilsson PM, Mancia G: Unattended blood pressure measurements in the Systolic Blood Pressure Intervention Trial: implications for entry and achieved blood pressure values compared with other trials. Hypertension 2016;67:808-812.

63 Myers MG: The great myth of office blood pressure measurement. J Hypertens 2012;39:1894-1898.

64 Andreadis EA, Agaliotis GD, Angelopoulos ET, Tsakanikas AP, Chaveles IA, Mousoulis GP: Automated office blood pressure and 24-h ambulatory measurements are equally associated with left ventricular mass index. Am J Hypertens 2011;24:661-666.

65 Filipovský J, Seidlerová J, Kratochvíl Z, Karnosová P, Hronová M, Mayer O, Jr: Automated compared to manual office blood pressure and to home blood pressure in hypertensive patients. Blood Press 2016;25:228-234. 
66 Myers MG, Godwin M, Dawes M, Kiss A, Tobe SW, Kaczorowski J: Measurement of blood pressure in the office: recognizing the problem and proposing the solution. Hypertension 2010;55:195-200.

67 Mancia G, Fagard R, Narkiewicz K, Redon J, Zanchetti A, Böhm M, et al: 2013 ESH/ESC guidelines for the management of arterial hypertension: the Task Force for the Management of Arterial Hypertension of the European Society of Hypertension (ESH) and of the European Society of Cardiology (ESC). Eur Heart J 2013; 34:2159-2219.

68 Stergiou GS, Parati G, Asmar R, O’Brien E, European Society of Hypertension Working Group on Blood Pressure Monitoring: Requirements for professional office blood pressure monitors. J Hypertens 2012;30:537-542.

69 Stergiou GS, Kollias A, Destounis A, Tzamouranis D: Automated blood pressure measurement in atrial fibrillation: a systematic review and meta-analysis. J Hypertens 2012;30:2074-2082.

70 Feig PU, Roy S, Cody RJ: Antihypertensive drug development: current challenges and future opportunities. J Am Soc Hypertens 2010;4:163-173.

71 Stergiou GS, Parati G, Vlachopoulos C, Achimastos A, Andreadis E, Asmar R, et al: Methodology and technology for peripheral and central blood pressure and blood pressure variability measurement: current status and future directions - Position statement of the European Society of Hypertension Working Group on blood pressure monitoring and cardiovascular variability. J Hypertens 2016;34:1665-77.

72 Myers MG, Tobe SW, McKay D, Bolli P, Hemmelgarn BR, McAlister FA: New algorithm for the diagnosis of hypertension. Am J Hypertens 2005;18:1369-1374.

73 National Institute for Health and Clinical Excellence: Hypertension, NICE Clinical Guidelines 127. London, UK: National Clinical Guidelines Centre; 2011.

74 Myers MG, Kaczorowski J, Paterson JM, Dolovich L, Tu K: Thresholds for diagnosing hypertension based on automated office blood pressure measurements and cardiovascular risk. Hypertension 2015;66:489-495.

75 Myers MG, Valdivieso M, Kiss A: Optimum frequency of automated blood pressure measurements using an automated hygmomanometer. Blood Press Monit 2008;13:333-338.

76 O’Brien E, Parati G, Stergiou G, Asmar R, Beilin L, Bilo G, et al: European Society of Hypertension position paper on ambulatory blood pressure monitoring. J Hypertens 2013;31:1731-1768.

77 Parati G, Stergiou GS, Asmar R, Bilo G, de Leeuw P, Imai Y, et al: European Society of Hypertension guidelines for blood pressure monitoring at home: a summary report of the Second International Consensus Conference on Home Blood Pressure Monitoring. J Hypertens 2008;26:1505-1526. 